\title{
Design and Implementation of an Improved Smoke Detection System
}

\author{
Dikio C. Idoniboyeobu, Chukwuka L. Onita, and Promise Elechi
}

\begin{abstract}
In this work, Proteus 8 professional software using 78L05 Voltage Regulator, first alert Brk 7010b smoke detector, relays, Arduino ide, Arduino UNO (ATmega328 microcontroller), 12VDC and 85 decibel sound buzzer Alarms, 5V NTE3019 light emitting diode (LED), resistors, vb.net program, 1N4007 diode was used to design an improved smoke detector. The approach of the design was to achieve a fast response to smoldering fire, low false alarm and low failure rate. The result of the design showed that it's an efficient smoldering smoke detection system with a uniform actuating alarm tested via simulating the design with Proteus software and Arduino ide c language burnt into the Arduino un (ATmega328 microcontroller). The simulation showed the working principle of the design by 5 volt being developed through the 78L05 voltage regulator and send across the relay coils, thereby actuating the common of the relays which are tied to pin 2 and pin 3 of the Arduino UNO digital input then resulting in the actuating of other sensors including the buzzers and Light emitting diodes. The virtual terminal displays the string $E$ as evidence that an email has been sent to those concern parties that can arrest the fire. Also from the result according to the measurement talking, the building has a flat horizontal ceiling of open areas with the area of the open office spaces ranging from $14 \mathrm{~m} 2$ to $107.2 \mathrm{~m} 2$ and also the height from the floor to the ceiling ranging from $2.92 \mathrm{~m}$ to $3 \mathrm{~m}$, so the maximum area one smoke detector covered was $50 \mathrm{~m} 2$ and the maximum distance between any points of an area to the smoke detector was $7.5 \mathrm{~m}$, maximum spacing between detectors was reduced when obstruction were present such as walls or partitions while minimum distance between detector and wall or partition was $500 \mathrm{~mm}$.
\end{abstract}

Index Terms-Diodes, Microcontroller, Arduino, Fire, Smuddering.

\section{INTRODUCTION}

The basic functions of a fire detection system is to notify the occupants of a building of an emergency conditions for evacuation purposes. Detect specific stages of fire outbreak such as smoldering or flaming. Actuating fire suppression systems and supervising fire suppression system. Alerting organized assistance such as the fire service departments to undertake firefighting operations and supervising processes for abnormalities that might cause fire. Automatic fire detection and control has become an important device used in securing property and business against fire which serves to reduce the fire in the building and industry. The primary

Published on December 31, 2017.

D.C. Idoniboyeobu is an Associate Professor in the Department of Electrical Engineering, Rivers State University, Port-Harcourt, Nigeria.

C.L. Onita is an M.Tech student in the Department of Electrical Engineering, Rivers State University, Port Harcourt, Nigeria.

P. Elechi is a lecturer with the Department of Electrical Engineering, Rivers State University, Port Harcourt, Nigeria. (e-mail: elechi.promise@ust.edu.ng). function of an automatic fire detector is to recognize a developing fire in a timely manner, and cause an alarm to notify the people present in the premises for an urgent evacuation [1].

According to [2], the primary purpose of fire protection system is to protect human life, and in case of most building, the secondary protection consideration is property, the easiest way of fire extinguishing is the fire detection system, so the speed at which the fire is detected is very vital because the faster the fire is detected the better the chances of the fire being extinguished thereby reducing damages of properties. It's very difficult to control and monitor fire in a very high and spaced building hence, intelligent fire detection system are important. Therefore, fire detection systems which are self-monitoring and have the ability to initiate both audible and visual warning in a spaced building are required.

According to [3], Smoke detector has been reviewed as a fundamental component of active fire detection strategy of modern commercial and residential building. In the 1970's, industries recorded increased use of smoke detectors and these growth was accompanied by several significant research projects that reinforced the life safety protection provided by smoke detectors, thereby providing significant evidence that supported increase in use of smoke detectors. Also in order to understand the response, working principle of these detectors in the environment, several researches was embarked.

Accurate prediction of smoke detector is a very significant way of assessing detector system performance because occupants and fire service notification can be dependent upon smoke detector response. Fire Dynamic Simulator software, can be used to predict the response of smoke detector [4].

Reference [5] stated that "fire loss data reveals that in buildings with automatic sprinklers, $96 \%$ were controlled and extinguished by these systems". Once there a fire, the fire detection system activates the alert thereby triggering the automatic sprinkler system. It's very important for fire protection system to be installed in all commercial building [6].

There are concerns associated with automatic smoke detection system arising from inappropriate techniques for quick notification, false noise tolerant and different sensor combinations [7]. Researchers have been studying fire taking place in various places such as residential area and commercial buildings [3], [5], [7].

\section{Review of Related works}

Numerous research studies of Smoke detection system have been carried out by different scholars in the past.

Reference [8] worked on intelligent photoelectric smoke 
detector. The concept of the work was on smoke alarm, using photoelectric sensor and UHF RF module for both transmitter and receiver part without any programming. It was fully hardware implemented with the output as LED to represent an alarm. The system was design to trigger an alarm once the smoke sensor senses smoke then the transmitter of RF module will be able to send the signal to other detector that will receive the signal. The system was to be controlled manually since there was no microcontroller. The system did not apply the concept of detecting smoldering fire as a means of detecting smoke faster and using a single relay to trigger all the buzzers in the system beside the system is not automatically controlled system since there is no microcontroller.

Reference [9] worked on intelligent smoke detector controlled by the microcontroller. The difference with [8] is that there was no RF application involved. Three main parts, the sensor, the microcontroller and the power device system were applied. The alarm system was powered by AC supply using small transformer to step down the voltage in order to achieve the most suitable power supply for the alarm system. These alarm system was designed to operate by sensing the smoke alarm then the microcontroller receives the signal through analog digital input/output and then trigger the alarm. Just like the previous, the system did not apply the concept of detecting smoldering fire as a means of detecting smoke faster and using a single relay to trigger all the buzzers in the system beside the system does not have an alternative supply source such as the DC supply.

Reference [10] worked on wireless smoke detection system. Photoelectric smoke detector was used for the design and the system was designed such that once smoke is detected, the alarm would be actuated and signal sent to other smoke detector in the vicinity. The individual relays in the other smoke detectors activates on sensing signals an in turn actuates other alarms. The system was battery operated only. The system did not apply the concept of detecting smoldering fire as a means of detecting smoke faster and using a single relay to trigger all the buzzers in the system, rather it used individual relays for each of the detectors thereby adding to the cost of the system and even causing a delay of other detectors to trigger an alarm because of individual relays.

Reference [11] worked on wireless security control system and sensor network for smoke and fire detection. The system was designed for smoke detector to activate alarm signal that would activate relay. The relay was connected to computer via parallel port that allows reading on alarm signal from smoke detector circuit. Receiving the alarm sends message to specified mobile station. PIC microcontroller, temperature sensor, smoke sensor, low battery sensor, transmitter and receiver were the hardware used for the design while the program and code was implemented using PIC microcontroller for the software component. The system did not apply the concept of detecting smoldering fire as a means of detecting smoke faster and using a single relay to trigger all the buzzers in the system rather the system was designed for smoke detector to activate alarm signal that would activate relay.

Reference [12] worked on wireless smoke detector system involving fabrication and programming process. The work was divided into two parts, the hardware and software. The hardware part consisted of PIC microcontroller, LED, LCD, air contaminant sensor and RF module while the software part, MPLAB IDE and PICKit2 were used to create and load the program. The system used air contaminant sensor to detect smoke and transmit RF signal to the receiver part thereby triggering the buzzer while the LED and LCD displays the condition of the detected smoke. The system did not apply the concept of detecting smoldering fire as a means of detecting smoke faster and using a single relay to trigger all the buzzers in the system rather the system used air contaminant sensor to detect smoke and transmit RF signal to the receiver part to trigger buzzer.

Reference [13] worked on optical smoke detector. The design was to detect the intensity of smoke and give a warning to people inside the building. Proteus was used for the design of the circuit and converted into printed circuit board. MPLAB IDE software was used for the programming and simulation of the microcontroller. The system was design for the smoke detector to detect smoke then the alarm and LED would be actuated. The system did not apply the concept of detecting smoldering fire as a means of detecting smoke faster and using a single relay to trigger all the buzzers in the system rather the concept of the system was to detect the intensity of smoke and trigger an alarm.

\section{MATERIALS AND METHOD}

\section{A. Description of Methods}

The design method adopted in this work was based on these stages of planning and application.

The smoke detection system circuit design was carried out using proteus 8 professional software and other components such as 5VDC 78L05 Voltage Regulator to power the system, first alert Brk 7010b smoke detector to sense smoldering fire, relays to send smoke detection signal, arduino IDE with $\mathrm{C}$ language for programming the microcontroller, 5V Arduino Uno board (ATmega328 microcontroller) to control the system by receiving signal of any smoke detection and actuating other sensors, 5VDC and 85 decibel sound buzzer Alarms, 5V NTE3019 light emitting diode (LED) to emit light, transistors, resistors, vb.net to monitor USB interface for receiving of email signal, 1N4007 diode. The approach of the design was to achieve a fast response to smoldering fire, low false alarm and low failure rate.

\section{B. Selection of Smoke Detector Type}

When selecting the needed smoke detection type for the design, it required taking a look at the building and analyzing the primary and secondary objectives which was done because different detectors perform differently according to their operation principles and the type of smoke they are to detect. Considering the type of smoke detector, the following requirements were carried out:

- Identifying all the fire threats in the building; it was necessary to work out the fire risk assessment which could set out potential hazards that could cause fire and areas of higher risk. From knowing how, where and what types of fire can start in the building gave an idea the appropriate fire detector to be chosen. 
- Considering the size and layout of the building; it was a very important and a key consideration before the detection system design started for overall coverage, size and the layout of the building.

- Early detection and intelligent technology; the early detection technology can be helpful in terms of notifying people and the fire department earlier which in effect can help save evacuation time, responses time and firefighting time to save the building from total fire destruction and loss.

- Cost, maintenance also plays a vital role in choosing type of fire detection system.

\section{Location of Fire Detection System}

Since design of smoke detectors are to detect smoke at an early stage to the following characteristics of heat, smoke, combustion, flame or gas and different detectors response differently to these mentioned characteristics, detectors should be selected for the best response to the effects of fires. Ceiling is a very good position of placing detectors since it's a very good location where early stages of fire will be located, also considering the effect of false alarm.

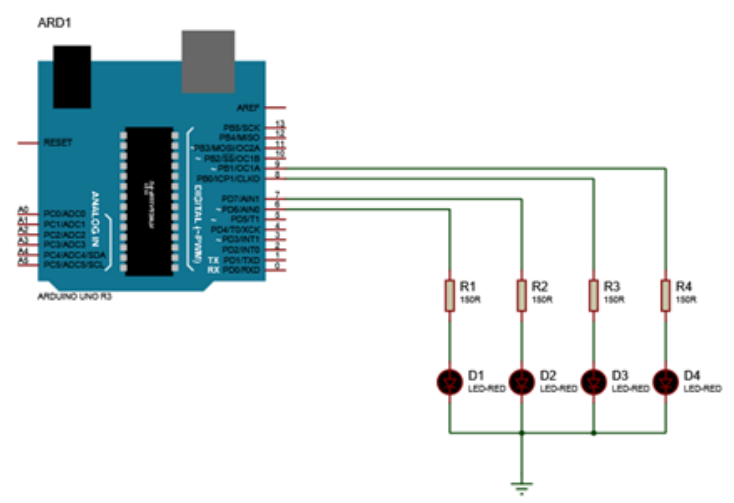

Fig. 1. Design at LED

As shown in Fig. 1, the LEDs have a fairly constant Voltage across them such as $2.0 \mathrm{~V}$ and $20 \mathrm{~mA}$ of current. The calculated Resistors are needed to prevent destruction of the LEDs by a High current. The slightest difference in LED or supply voltage may cause the LED to light very dim, very bright, or even destroy it. The series resistors helps to ensure that slight differences in voltage have only a minor effect on the LEDs current provided that the voltage drop across the resistors are large. LED's D1, D2,D3 and D4 are tied to R1, R2, R3 and R4 and are connected to the Arduino so that when they receive a low, it means they are off and when they receive a high, it means they have been forward biased and therefore they would come up. That is the working principle of the LED's in various locations.

\section{LED ratings}

Forward Voltage drop of an LED $V_{F}=2.0 \mathrm{~V}$

Forward Current of an LED $I_{F}=20 m A$

Output High Voltage of Arduino $V_{O H}=5$

From Kirchhoff's voltage law

$V_{O H}-I_{F} R_{1}-V_{F}=0$

$$
5-20 \times\left(R_{1}\right)-2=0
$$

$$
\begin{aligned}
& 3-20 \times\left(\mathrm{R}_{1}\right)=0 \\
& R_{1}=\frac{3}{20} m A \\
& R_{1}=150 \Omega
\end{aligned}
$$

Therefore from Resistance $R_{1}$ to $R_{4}=150 \Omega$

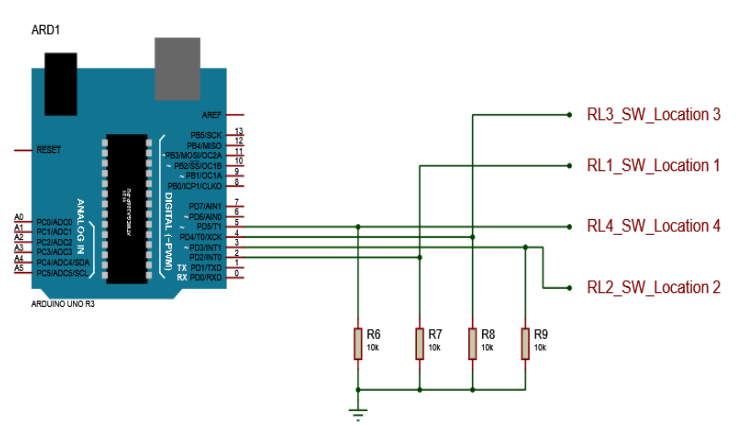

Fig. 2. Design at the Pull-Down Switches

The reasons for resistor R6, R7, R8 and R9 connected to these different locations as shown in Fig. 2 is such that the voltage that is being sent from the voltage regulator U1, that's 78L05 would be dropped across these resistors. The idea of that is to avert a situation where we would be having a case of floating potentials. Floating potentials arises where a pin on TTL (Transistor Transistor Logic) is left floating, as a result it could take a static electricity from the atmosphere and assume its state. So tying it to the terminals of each of the location connecting it to ground and by so doing elimination the idea of floating potentials

Since

$V=I R$

Output High Voltage of Arduino $V_{O H}=5$

Forward Current $I=10 \mathrm{~mA}$

$R=\frac{V}{I}=\frac{5}{10 m}$

$R=500 \Omega$

Therefore from Resistance $R_{6}$ to $R_{9}=500 \Omega$

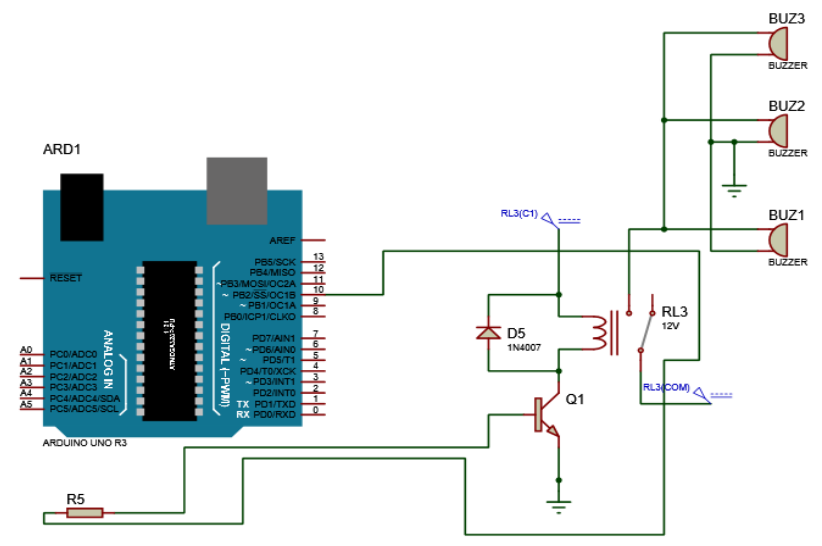

Fig. 3. Design of the Alarm system

Fig. 3 shows that these alarms would only be triggered when it receives a high from any of the locations (say 3 
locations) designed. So these alarm section is controlled by a transistor Q1 and it's tied to other biasing component such as R5, relay RL3 and Diode D5, together they function and bias a transistor in order for it to operate as a switch being a device that can come on and go off. The working principle is that when R5 through pin 10 receives a high (1), it means that the transistor Q1 condition for the transistor to be in saturation is satisfied and that causes the relay contact to move from normally closed to normally open, as such energizing buzzer 1,2 and 3 . The condition for saturation is that the collector base junction must be biased why the base emitter junction must be reversed forward biased. That's why when a high (1) is at pin 10 , which is connected to the base, the transistor will operate in a saturation region of the DC load line and as such it becomes a conductor and a potential would be established across the relay which will cause it to be actuated. The reverse is the case when a low (0) is being sent to the pin 10, which the base emitter junction becomes reversed biased and when it's reversed biased its collector base junction as well is also reversed biased, common emitter configuration transistor, it means that the transistor is operating at its cut of region. The transistor Q1 will function as am open circuit as such the buzzers will remained off.

The relay selected for the circuit is the smallest commercially available on shelf.

\section{Relay Specification}

Power Supply Voltage, $V_{C C}=12 V D C$

Coil Resistor, $R_{L 3}=960 \Omega$

Collector Current, $I_{C}=$ ?

Impendence $=Z=R+j X$

but $j X$ tends to Zero,

Therefore $Z=R$

By applying KVL to the output circuit the following equation results:

$V_{C C}-I_{C} R_{L 3}-V_{C E}=0$

Equation (5) is the output loop equation. Since,

$$
\begin{aligned}
I_{C} & =\frac{V_{C C}}{R_{L 3}} \\
I_{C} & =\frac{12}{960} \\
I_{C} & =12 \cdot 5 \mathrm{~mA}
\end{aligned}
$$

The same with the rated current

Since the same supply voltage, $\left(V_{C C}\right)$ also determines the maximum collector current, $I_{C}$ when the transistor is switched fully "ON" (saturation), $V_{C E}=0$

From $V_{C C}-I_{C} R_{L 3}-V_{C E}=0, \quad 12-\mathrm{I}_{\mathrm{C}} \times(960)-0=0$

Where $V_{C E}=0,12=\mathrm{I}_{\mathrm{C}} \times(960)$
Therefore, maximum collector Current:

$I_{C}=\frac{12}{960}=12 \cdot 5 \mathrm{~mA}$

Base Current $I_{B}$, Collector Current $I_{C}$ and Emitter Current $I_{E}$, DC current gain,

$\beta=h f e=\frac{I_{C}}{I_{B}}$

$h f e=\frac{12 \cdot 5}{\mathrm{I}_{\mathrm{B}}}, h f e=100$ and $I_{C}=12 \cdot 5 \mathrm{~mA}$

Therefore, $I_{B}=\frac{I_{C}}{h f e}=\frac{12 \cdot 5 \mathrm{~m}}{100}$

Therefore, Base Current, $I_{B}=0 \cdot 125 \mathrm{~mA}$, From;

$V_{O H}-I_{B} R_{5}-V_{B E}=0$

Where $V_{O H}=5 \mathrm{~V}, I_{B}=0 \cdot 125 \mathrm{~mA}, V_{B E}=0.7$

$5-0 \cdot 125 \mathrm{~m} \times\left(\mathrm{R}_{5}\right)-0 \cdot 7=0,4.3-0125 \mathrm{~m} \times\left(\mathrm{R}_{5}\right)=0$

$R_{5}=\frac{4 \cdot 3}{0 \cdot 125 \mathrm{~m}} \cdot \quad$ Therefore, $\quad R_{5}=34 \cdot 4 K \Omega$.So

$R_{5}=30 \mathrm{~K} \Omega$ approximately stand.

$\mathrm{R} 5$ must be less than $34.4 \mathrm{~K} \Omega$, to drive the transistor deep into saturation. Also transistor BC547 was selected because its gain is 200 and saturation current is $200 \mathrm{~mA}$ and a transient (flyback) diode of $1 \mathrm{~N} 4007$ was used for both relays.

\section{E. Design of Smoke Detection Circuit}

The theory of the design was based on the working principle of the First alert 7010b smoke detection system which is generally more sensitive at detecting large smoke particles (smoldering fire).

The design also applied the NPN transistor theory where the circuit operates on principle of saturation of the collector base junction to be biased why the base emitter junction to be reversed forward biased. That is why a high $(5 \mathrm{~V})$ of the Arduino UNO is at pin 10, which is connected to the base, the transistor operates in a saturation region of the DC load line and as such it becomes a conductor and a potential is established across the relay which actuates it. The reverse is the case when a low (0) of the Arduino UNO is sent to the pin 10, the base emitter junction becomes reversed biased and its collector base junction is also reversed biased (common emitter configuration transistor); it means that the transistor is operating at its cut of region. The transistor Q1 will function as an open circuit as such the buzzers will remained off.

\section{F. Selection of Components}

The selection of the electronic components was based on the ATmega 328 Arduino microcontroller which accepts supply voltage ranging from $5 \mathrm{~V}$ to $12 \mathrm{~V}$. A $5 \mathrm{~V}$ regulator was used to supply the needed voltage of the system. In the case of the Light Emitting Diode, the recommended forward Voltage drop of an LED needed to light very bright without destruction is $2 \mathrm{~V}$, the forward current of that same LED is $20 \mathrm{~mA}$ and output high Voltage of Arduino 5V. From the 
LED selection, the following calculations were done to ascertain the required resistors.

$$
\begin{aligned}
& V_{O H}-I_{F} R_{1}-V_{F}=0 \\
& 5-20 \times\left(\mathrm{R}_{1}\right)-2=0 \\
& 3-20 \times\left(\mathrm{R}_{1}\right)=0 \\
& R_{1}=\frac{3}{20} m A \\
& R_{1}=150 \Omega
\end{aligned}
$$

Therefore from Resistance $R_{1}$ to $R_{4}=150 \Omega$. In the case of relays $12 \mathrm{~V}$ was used because the complementary circuits attached are of $12 \mathrm{~V}$ which can easily be found in the market. This calculation was done to determine the holding current that can energize the relay contact to open and close.

$$
V_{C C}-I_{C} R_{L 3}-V_{C E}=0
$$

\section{Since}

$$
I_{C}=\frac{V_{C C}}{R_{L}}, \quad I_{C}=\frac{12}{960}, I_{C}=12.5 \mathrm{~mA}
$$

From this calculated holding current of $12.5 \mathrm{~mA}$, the transistor was selected based on the value greater than the holding current, also considering the fact that the design involves a coil having an integral of inductive load which absorbs twice the amount of current when switched on and availability in the market.

\section{RESULTS AND DISCUSSION}

\section{A. Smoke Detection Circuit Design}

Proteus 8 Professional, an Electronic Design Automation (EDA) tool including schematic capture, simulation and PCB Layout modules was used for the design of the smoke detection system circuit with other required components such as Arduino UNO R3 (Microcontroller), Smoke Sensor (First Alert BRK 7010B hardwire smoke detector), Buzzers (Alarm), LED-Red, Resistors, Transistor, Voltage Regulator 78L05 (Power), Relay, Virtual Terminal, Button, 1n4007, BC547, Minres1k, Vb.net. Fig. 4 shows the designed circuit diagram.

The circuit is designed to control four (4) locations and each of the locations attached with a total number of 18 sensors for an arrays of smoke detectors in series according to the First Alert BRK 7010B hardwire smoke detector data sheet. A relay is attached with the 18 sensors; this is because, once smoke has been detected by any of the sensors, it sends signal to the microcontroller (Arduino UNO Board) which will immediately actuate the other sensors.

The circuit is simulated by pushing the push button switch just by the relay, thereby actuating the common of the relay that was formerly in the normally closed contact region moving to the open terminals, resulting in the connection of the terminal one (1) of the 78L05 voltage regulator to the normally open relay connected to pin 2 of the Arduino. A 5V connected the input high of the Arduino from the voltage regulator to the Arduino digital input, makes the Arduino to experience change of state from zero (0) to one (1). The arduino uno immediately actuates the other sensors which causes the alarms to be triggered. The algorithm (programming) is watching out for change of state from low level to a high level, sensing of that results to $\mathrm{ON}$ the LED (Light Emitting Diode) emitting light in the particular location that receive the high (1). So one way in which the sensors that detected a smoke and triggered an alarm can be known is through virtual inspection of the LED on the smoke detector that is ON.

LED's $\mathrm{D}_{1}, \mathrm{D}_{2}, \mathrm{D}_{3}$, and $\mathrm{D}_{4}$ are connected through $\mathrm{R}_{1}, \mathrm{R}_{2}$, $\mathrm{R}_{3}$ and $\mathrm{R}_{4}$ connected to the Arduino uno so that when there is a low (0), it means they are off and when there is a high (1), it means forward biase and therefore would come up. That is the working principle of the LED's in various locations. The LED that comes up indicates the particular location smoke has been detected.

The right hand side of Fig. 4 are multiple numbers of alarms which are represented as Buzzers and are connected to a single relay $\left(\mathrm{RL}_{5}\right)$ so that once that relay is actuated, all the alarm (Buzzer) in the building will be triggered. The alarm section is controlled by transistor Q1 which is connected to other biasing component such as $\mathrm{R}_{5}$, relay $\mathrm{RL}_{5}$ and Diode $\mathrm{D}_{5}$, together they function and bias the transistor in order for it to operate as a switch. How it works is that, when $R_{5}$ through pin 10 receives a high (1), it means that the transistor Q1 condition for the transistor to be in saturation is satisfied and that causes the relay $\left(\mathrm{RL}_{5}\right)$ contact to move from normally closed to normally open, as such energizing buzzer 1,2 , and 3 . When a high is at pin 10 , which is connected to the base, the transistor will operate in a saturation region of the DC load line and as such it becomes a conductor and a potential would be established across the relay which will cause it to be actuated. The reverse is the case when a low (0) is at pin 10 , the base emitter junction becomes reversed biased and its collector base junction as well is also reversed biased (common emitter configuration transistor); this means that the transistor is operating at its cut off region. The transistor Q1 will function as an open circuit as such the buzzers will remain OFF.

The virtual terminal which is a module through which USB is connected, it helps to indicate what is being sent from the serial port to the USB port of the hardware. Once a data has been sent to the USB port, and is received by Vb.net application program developed for this purpose, an email would be sent. All these are done automatically through the program code developed for this work. The email capability is achieved by sending letter E chosen during the development of the program to pre-configured emails to first respondent which is fire fighters.

The reason for resistor $R_{6}, R_{7}, R_{8}$ and $R_{9}$ connected to these different locations is that the voltage that is being sent from the 78L05 voltage regulator would be dropped across these resistors. The idea of that is to avert a situation of floating potentials. Floating potentials arises where a pin on TTL (Transistor Transistor Logic) is left floating as a result it could take a static electricity from the atmosphere and assume its state. 


\section{B. Smoke Circuit Simulation}

First Alert BRK 7010B hardwire smoke detector circuit simulation was done by completing the compilation (AVRGCC) of the Arduino IDE code. Then, the result of this process was the hex file (See Fig. 3). This file contained the specific bytes ready to write to the program memory on the Arduino board which was transmitted to the Arduino, the hex file was copied and burnt to the Arduino UNO (See Fig. 4) thereby programming the device and these data were used by the embedded system to enable the system simulate.

Simulation of this circuit was done by pushing the push button switch just by the relay $\mathrm{RL}_{1}$ and $\mathrm{RL}_{2}$ of Fig. 5, then, 5 $\mathrm{V}$ passes through the 78L05 voltage regulator and send across the relay coils, thereby actuating the common of the relays that was formerly in the normally closed contact region moving to the open terminals connected to pins 2 and 3 of the Arduino uno digital input causing the Arduino to experience change of state from zero (0) to one (1), hence actuating other

Sensors and the buzzers. The 5V goes across R5 through pin 10 thereby satisfying the transistor Q1 condition to be in saturation, thereby making relay $\mathrm{RL}_{3}$ contact to move from normally closed to normally open, as such energizing buzzer 1, 2 and 3. Immediately the Light emitting diode $\mathrm{D}_{2}$ and $\mathrm{D}_{3}$ are activated. This implies that the alarm was triggered by the location 1 and location 2.The LED's $\mathrm{D}_{1}, \mathrm{D}_{2}, \mathrm{D}_{3}$, and $\mathrm{D}_{4}$ are connected through $\mathrm{R}_{1}, \mathrm{R}_{2}, \mathrm{R}_{3}$ and $\mathrm{R}_{4}$ and to the Arduino uno so that when they receive a low (0), (OFF) and when they receive a high $(1),(\mathrm{ON})$, it means they have been forward biased and therefore they would come up. That is the working principle of the LED's in various locations. And of course which ever LED's that comes up tells the particular location smoke has been detected. This is done automatically through the algorithm of the program code that has been developed and burnt into the Arduino. The string E displayed in the virtual terminal is evidence that an email has been sent to those concern parties that can arrest the fire as shown in Fig. 5 and Fig. 6 shows the response rate for rooms 1 through 7 .

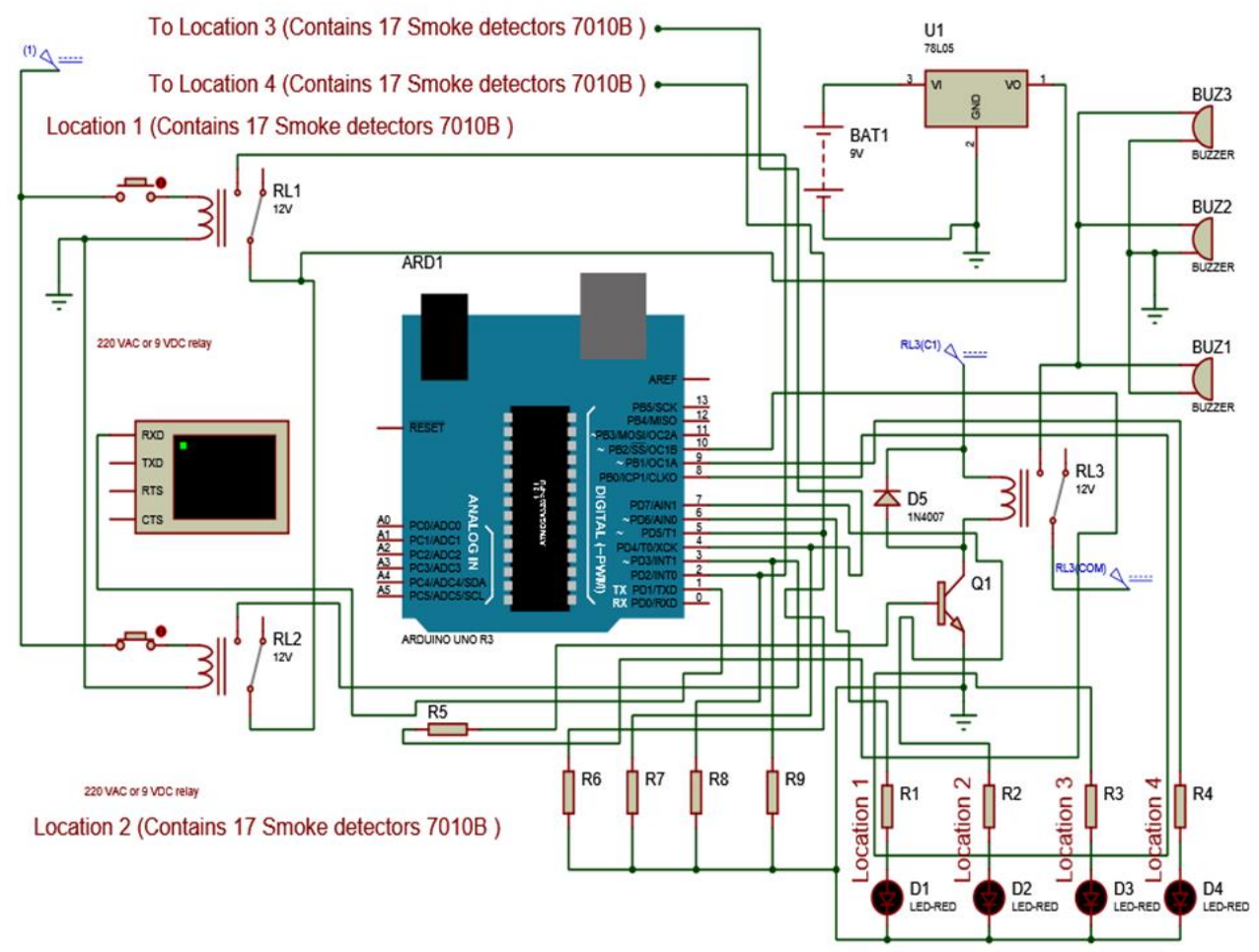

Fig. 4. Smoke Detection Circuit Diagram 


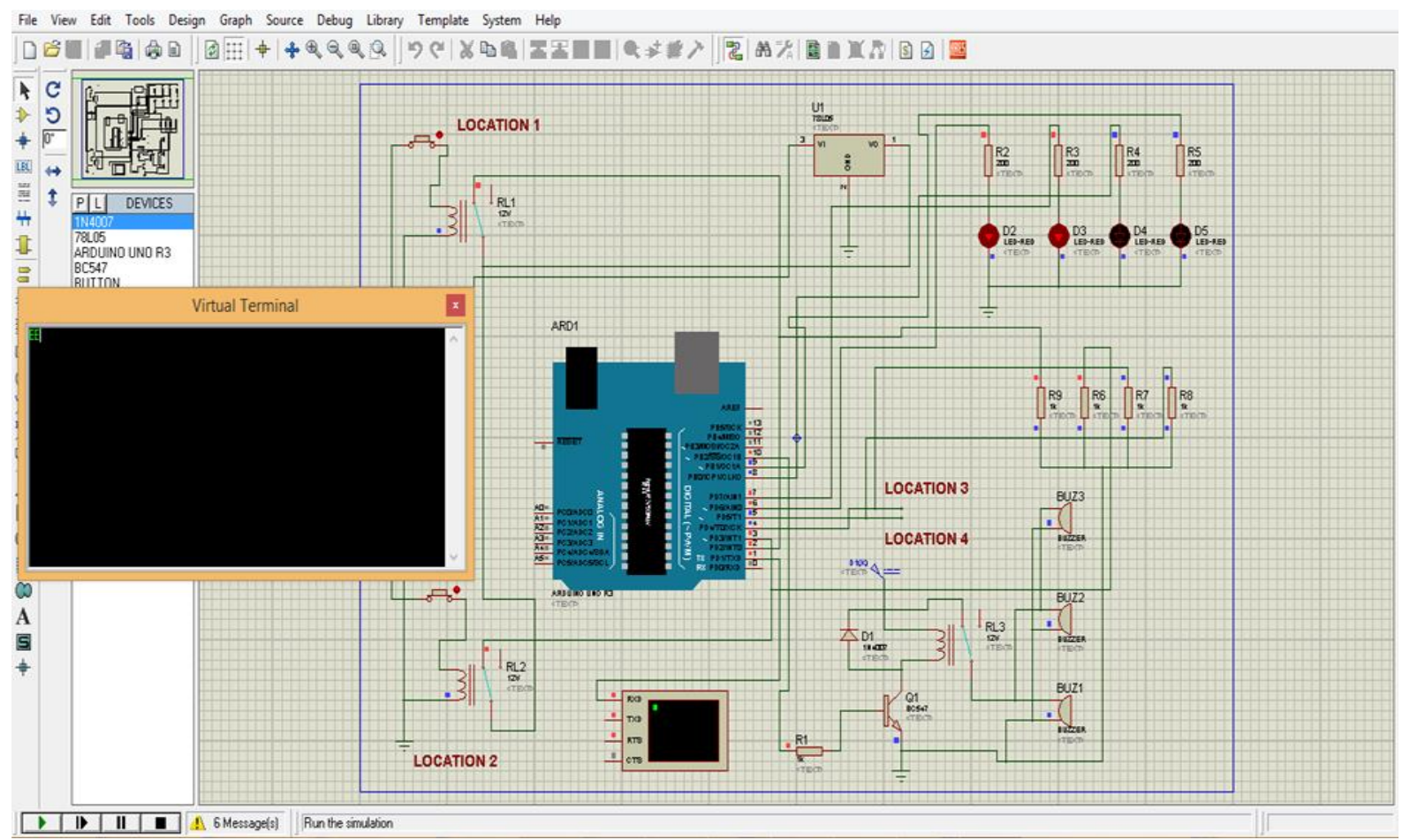

Fig. 5. Smoke Circuit Simulation Diagram

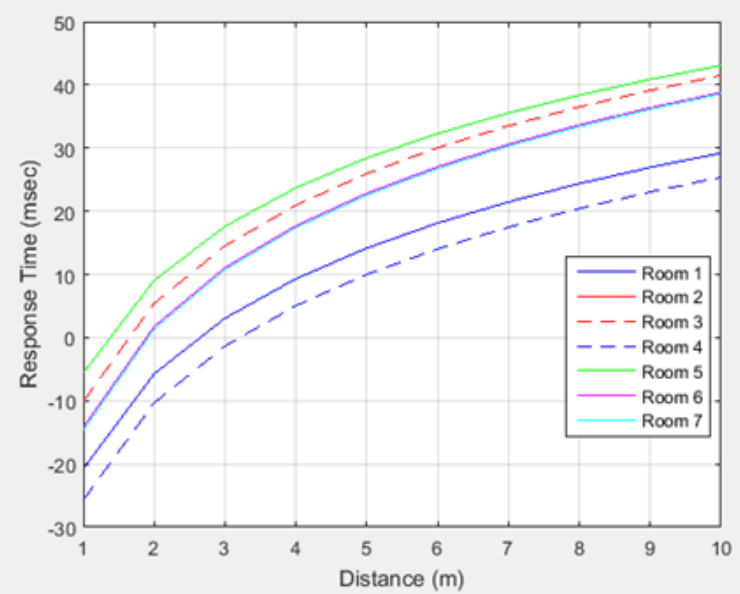

Fig. 6. Response Rate in Different Rooms

\section{CONCLUSION AND RECOMMENDATIONS}

\section{A. Conclusion}

This study is to design an improved smoke detection system, capable of providing real-time surveillance, monitoring, and notifying people in the premises of emergency conditions for evacuation. The simulation of the smoke detection circuit provided the insight into the behavior of the circuit and validated my result by energizing the 3 buzzers, LED $\left(\mathrm{D}_{2}\right.$ and $\left.\mathrm{D}_{3}\right)$ emitting light and virtual terminal displaying string $\mathrm{E}$, evidence of the mailing part which helps to inform or send pre-configured emails to fire fighters, etc.

The area covered was $50 \mathrm{~m} 2$ and the maximum distance between any points of an area to the smoke detector was $7.5 \mathrm{~m}$, maximum spacing between detectors was reduced when obstruction were present such as walls or partitions while minimum distance between detector and wall or partition was $500 \mathrm{~mm}$. The height of the building considered ranged from $2.92 \mathrm{~m}$ to $3 \mathrm{~m}$ which was far less than the maximum recommended height of $10.5 \mathrm{~m}$ for First Alert BRK 7010B hardwire sensor.

\section{B. Recommendations}

In view of the investigations and conclusion of this study, the following recommendations may hold well for improved smoke detection system

1. Maintenance procedures should always be carried out to ascertain the functionality of the equipment so that at the moment of fire outbreak, this equipment will not fail to operate and also to reduce unwanted alarms and malfunction of equipment.

2. Testing of the effectiveness and working condition of these equipment's are very necessary and need to be carried out by a qualified professional on a regular basis set out in a formal fire risk assessment. Inspection and servicing of fire alarm should always take place at least 2-4 times per year

\section{REFERENCES}

[1] M. Kironji, "Evaluation of Fire Protection Systems in Commercial Buildings for Fire Safety Optimization", International Journal of Scientific and Research Publication, vol. 5, No. 10, pp. 2250-3153, 2015.

[2] V. Pati, S. Joshi, R. Sowmianarayanan, M. Vedavahi, \& R. Rana, "Simulation of Intelligent Fire Detection and Alarm System for a Warship". Institute of Armament Technology. Vol. 39, pp. 79-94, 1989.

[3] G. Heskestad, "Escape Potentials from Apartments Protected by Fire Detectors in High-Rise Building", Department of Housing and Urban Development, Factory Mutual Research Corp., Norwood, Massachusetts. Final Technical Report, 1984.

[4] A. Lerardi, \& J. Barnett, "A Methodology for Predicting Smoke Detector Response". WPI Center for Fire Safety Studies, Worcester, 2000. Retrieved from: ierardi@wpi.edu, on 2nd April, 2017.

[5] M. Wieder, \& C. Smith, "Fire Inspection and Code Enforcement", (6th Edition.), Oklahoma City, Fire Protection Publication, Oklahoma State University, 1998.

[6] N. Langewisch, N. "A Review of Automatic Sprinkler Systems and Fire Detection Systems within Missouri", Occupational Safety in the Fire Service. University of Central Missouri, 2011. 
[7] E. Omorogiuwa and P. Elechi "GSM Based Intelligent Home Security System for Intrusion Detection", International Journal of Engineering and Technology, Vol. 4 No. 10, pp. 596-605, 2014.

[8] R. Norsuraya, "Wireless Smoke Alarm Detector", Bachelor Degree Project Work, Department of Electrical Engineering, Faculty of Engineering, University Technology, Malaysia, 2012.

[9] W. Yingzhuo, Z. Shaowu, \& L. Yanwei, "Smoke Detection Based on Multi-Spectral Images. Spectroscopy and Spectral Analysis, vol. 30 no. 4, pp. 1061-1064, 2010.

[10] O. Khalifa, S. Khan, \& N. Usman, "Wireless Smoke Detection System", Proceedings of the International Conference on Computer and Communication Engineering. International Islamic University Malaysia, pp. 13-15, 2008.

[11] M. Lipu, T. Karim, L. Rahman, \& F. Sultana, "Wireless Security Control System and Sensor Network for Smoke and Fire Detection", Advanced Management Science, Proceedings of IEEE International Conference, vol. 3, no. 153, pp. 9-11, 2010.

[12] K. Fatimah, "Wireless Smoke Detector System". Bachelor Degree Project Work, Department of Electrical Engineering, Faculty of Engineering, University Technology Malaysia, 2011.

[13] C. Belo, J. Aurea, F. Rangel, J. Alda, \& N. Grace, "Design of Fire Protection, Particularly Fire Sprinkler System in South Building of Mupua", Institute of Technology, Environmental and Sanitary Engineering, vol. 1, pp. 1-10, 2014.

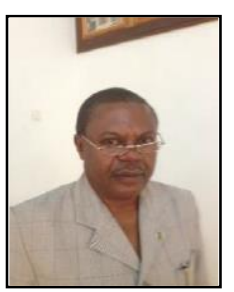

Dikio C. Idoniboyeobu is an Associate Professor in the Department of Electrical Engineering, Rivers State University, Port-Harcourt, Nigeria He holds B. Eng Degree in Electrical Engineering, Ahmadu Bello University, Zaria, Nigeria; M. Sc. and PhD Degrees in Electrical Engineering, University of Manchester, United Kingdom

$\mathrm{He}$ is registered with Council for the Regulation of Engineering in Nigeria (COREN), and a member of several Professional Organizations.

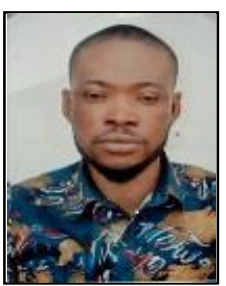

Chukwuka L. Onita received his B.Tech in Electrical Engineering from Rivers State University, Nigeria in 2012. He is currently an M.Tech student in the Department of Electrical Engineering, Rivers State University, Port Harcourt, Nigeria.

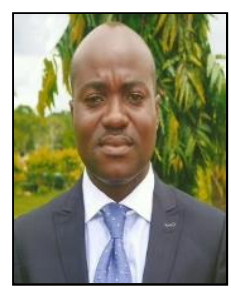

Elechi Promise received his B.Eng and M.Eng degrees in Electrical/Electronic Engineering from University of Port Harcourt, Choba, Rivers State, Nigeria in 2006 and 2011 respectively. $\mathrm{He}$ is currently a Ph.D Student in Electronic and Telecommunication Engineering of University of Benin. He is a corporate member of the Nigerian Society of Engineers (NSE), International Association of Engineers (IAEng), Institute of Engineering and Technology (IET), and Nigerian Institution of Electrical/Electronic Engineers (NIEEE). He is also registered practicing Engineer with the Council for the Regulation of Engineering in Nigeria (COREN). His current research interest is on Radio Propagation for Mobile Communications, GSM Technology, Microwave Propagation, Signal Analysis, NanoTechnology and ICT. He is currently a Lecturer in the Department of Electrical and Computer Engineering, Rivers State University, Port Harcourt, Nigeria. Elechi can be reached on elechi.promise@ust.edu.ng, and +2348035476478 